DOI: https://doi.org/10.24867/01EF01Milovanovic

\title{
TRETMAN OTPADNE VODE FLEKSO ŠTAMPE PRIMENOM FENTON-SLIČNOG PROCESA
}

\section{TREATMENT OF FLEXO PRINTING WASTEWATER BY USING A FENTON-LIKE PROCESS}

\author{
Vanja Milovanović, Miljana Prica, Fakultet tehničkih nauka, Novi Sad
}

\begin{abstract}
Oblast - GRAFIČKO INŽENJERSTVO I DIZAJN
Kratak sadržaj - U radu je prikazano tretiranje otpadne vode Fenton-sličnim procesom primenom nano nula valentnog gvožđa kao katalizatora. Uzorak otpadne vode generisane nakon štampanja cijan bojom uzet je iz flekso štamparije koja se nalazi u Novom Sadu. „Zelena” sinteza nanomaterijala je sprovedena korišćenjem opalog lišća sa drveta hrasta koje raste u Nacionalnom parku Fruška Gora. Ispitivanje efikasnosti obezbojavanja vodenog rastvora grafičke boje vršeno je serijom eksperimenata na aparaturi za JAR test.
\end{abstract}

Ključne reči: cijan boja, Fenton proces, nano nula valentno gvožđe, tretman realnog efluenta, flekso štampa

Abstract - In this paper a treatment of wastewater with Fenton-like process by using nano zero valent iron as catalyst was analysed. A sample of wastewater generated after printing with cyan dye was taken from a flexo printing facility in Novi Sad. The "green" synthesis of nanomaterial was carried out using leaves of oak tree that grew in Fruška Gora National Park. The efficiency of decolorization of printing dye aqueous solution was performed by series of experiments on the JAR test apparatus.

Keywords: cyan dye, Fenton process, nano-zero valent iron, real effluent treatment, flexo printing

\section{UVOD}

Obojene otpadne vode u štamparijama nastaju nakon pranja valjaka štamparske mašine i posuda za čuvanje boje, pri čemu se nakon završenog procesa štampe ispuštaju u recipijent $i$ na taj način zagađuju životnu sredinu u određenoj meri. Pored estetskog problema veliki problem u pogledu boja jeste njihova adsorpcija i refleksija sunčeve svetlosti i ometanje fotosinteze vodenih biljaka što utiče na značajan porast bakterija do nivoa nedovoljne biološke degradacije nečistoća u vodi i samim tim remećenja ekološke ravnoteže. Boje mogu imati akutne i hronične efekte na izložene organizme u zavisnosti od trajanja izloženosti i koncentracije boje [1].

Jedna od najefikasnijih metoda prečišćavanja otpadnih obojenih voda jeste Fenton proces, koji spada u oksidacione metode koje se koriste za oksidaciju/koagulaciju voda sa visokim sadržajem teško degradabilnih jedinjenja.

\section{NAPOMENA:}

Ovaj rad proistekao je iz master rada čiji mentor je bila dr Miljana Prica, vanr. prof.
Fentonov proces se izdvaja kao uspešan, jeftin i lak za rukovanje u poređenju sa ostalim procesima oksidacije. Sam proces se bazira na generisanju hidroksil radikala $\mathrm{u}$ reakciji između jona gvožđa i vodonik peroksida. Prednost Fenton procesa se ogleda u tome što nije neophodna upotreba energije za aktiviranje vodonik-peroksida, jer se reakcija odvija na atmosferskom pritisku i sobnoj temperaturi. Ova metoda zahteva relativno kratko reakciono vreme i upotrebu reagenasa koji su jednostavni za rukovanje. Pored toga, gvožđe je netoksičan i rasprostranjen element, vodonik-peroksid je jednostavan za manipulaciju i bezbedan po životnu sredinu i skoro da ne daje rezidual nakon tretmana. Fenton procesom se može postići potpuna mineralizacija organskih supstanci do jedinjenja koja nisu štetna, tj. $\mathrm{CO}_{2} \mathrm{i}$ vode [2].

Veliku primenu katalizatora u Fenton procesu imaju i nanomaterijali, tj. čestice nano nula valentnog gvožđa (eng. nano zero valent iron - nZVI). Nanomaterijale karakteriše znatno povećanje specifične površine $u$ funkciji mase, što omogućava upotrebu manje mase za postizanje istih ciljeva. Teoretski se na taj način može uštedeti na količini upotrebljenog materijala i na energiji, a samim tim dolazi do smanjenja troškova remedijacije.

Nano nula valentno gvožđe se pokazalo efikasno u degradaciji širokog spektra kontaminanata vode poput halogenovanih ugljovodonika, nitroaromatičnih jedinjenja, azo-boja, perhlorata, nitrata i različitih jona teških metala [3].

Predmet istraživanja rada je tretiranje otpadne vode nastale nakon štampe cijan bojom, Fenton-sličnim procesom, uz primenu nano nula valentnog gvožđa kao katalizatora. Uzorak otpadne vode generisane nakon štampanja cijan bojom uzet je iz flekso štamparije koja se nalazi u Novom Sadu.

\section{MATERIJALI I HEMIKALIJE}

Uzorak otpadne vode generisane nakon štampanja cijan bojom uzet je iz flekso štamparije koja se nalazi u Novom Sadu. Obojena otpadna voda nastaje nakon pranja valjaka štamparske mašine i posuda za čuvanje boje, pri čemu se, nakon završenog procesa štampe, voda ispušta u recipijent i na taj način zagađuje životnu sredinu u određenoj meri.

Vodonik peroksid (30\%) je proizveden od strane NRK inženjeringa, Srbija, dok su natrijum-hidroksid (>98,8\%) i sumporna kiselina $(>96 \%)$ proizvedeni od strane J.T. Bakera. 
Za pripremu radnih rastvora željenih koncentracija korišćena je dejonizovana voda. Odabrana flekso grafička boja (C.I.: PB15:3, hemijska formula: $\mathrm{C}_{32} \mathrm{H}_{16} \mathrm{CuN}_{8}$, molarna masa: $576,07 \mathrm{~g} / \mathrm{mol}, \lambda_{\max }: 636 \mathrm{~nm}$ ) pripada grupi ftalocijanskih boja i proizvedena je od strane Flint grupe. Strukturna formula cijan boje je prikazana na slici 1 .

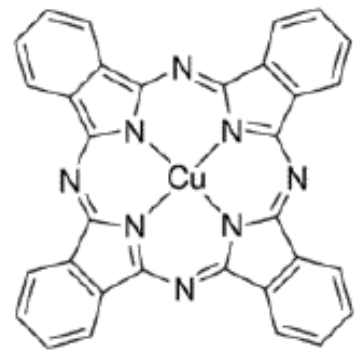

Slika 1. Strukturna formula cijan boje

\section{SINTEZA NANOMATERIJALA}

Prikupljeno lišće je najpre samleveno u kuhinjskom blenderu i prosejano kroz sito dimenzija pora $2 \mathrm{~mm}$. Dobijeni materijal je sušen 48 sati na temperaturi $50{ }^{\circ} \mathrm{C}$. Sinteza nanomaterijala iz ekstrakta lišća hrasta je sprovedena prema proceduri koju su postavili Machado i sar. [4].

\section{EKSPERIMENT}

\subsection{Efikasnost obezbojavanja}

Ispitivanje efikasnosti obezbojavanja vodenog rastvora grafičke boje vršeno je serijom eksperimenata na aparaturi za JAR test (FC6S Velp scientific, Italija). Sva spektrofotometrijska merenja su vršena korišćenjem UVVIS sprektrofotometra UV-1800PG Instruments Ltd T80+ UV/VIS, model: UV 1800 (Shimadzu, Japan). Merenje pH vrednosti izvršeno je pomoću AD110 Adwa instrumenta. Efikasnost obezbojavanja izračunata je prema jednačini (1):

$$
\mathrm{E}(\%)=\mathrm{A}_{0}-\mathrm{A}_{\mathrm{t}} / \mathrm{A}_{0} * 100
$$

gde je: $A_{0}$ - početna apsorbancija obojenog vodenog rastvora boje ili efluenta; $A_{t}-$ apsorbancija vodenog rastvora uzorka nakon sprovedenog Fenton procesa.

\subsection{Fizičko-hemijska analiza realnog efluenta pre i nakon tretmana}

Vrednost $\mathrm{pH}$, provodljivost $\mathrm{i}$ temperatura su izmereni pomoću instrumenta AD110 Adwa, dok je mutnoća izmerena pomoću Turb 439 IR WTWE. Hemijska potrošnja kiseonika (HPK) je određena volumetrijskom metodom pomoću kalijum-dihromata, u kiseloj sredini, uz srebrosulfat kao katalizator - SRPS ISO 6060: 1994. Biološka potrošnja kiseonika (BPK) nakon 5 dana na temperaturi od $20^{\circ} \mathrm{C}$ je sprovedena putem manometrijske metode - H1.002, korišćenjem instrumenta Velp Scientifica Italia, Lowibond and WTW. Za određivanje toksičnosti je korišćena metoda ISO 11348.

\section{REZULTATI I DISKUSIJA}

\subsection{Evaluacija modela}

U cilju karakterizacije sistema pod uticajem različitih procesnih uslova: koncentracije boje, koncentracije nZVI, pH vrednosti i koncentracije vodonik peroksida na efikasnost obezbojavnja vodenog rastvora cijan flekso grafičke boje sprovedeno je 13 eksperimenata, a rezultati su prikazani u tabeli 1. Dobijeni rezultati ukazuju da je postignut širok opseg efikasnosti obezbojavanja od 1,67 $83,45 \%$. Na ovaj način je potvrđena pretpostavka da sam proces uklanjanja boje u velikoj meri zavisi od primenjenih eksperimentalnih uslova, odnosno da pojedinačni parametri u određenoj meri doprinose efikasnosti Fenton procesa.

Tabela 1. Efikasnost obezbojavanja pri različitim eksperimentalnim uslovima

\begin{tabular}{|c|c|c|c|c|c|}
\hline Proba & $\begin{array}{c}\text { Koncentracija } \\
\text { boje [mg/l] }\end{array}$ & $\begin{array}{c}\text { Koncentracija } \\
\text { gvožđa [mg/l] }\end{array}$ & $\begin{array}{c}\text { Koncentracija } \\
\mathbf{H}_{\mathbf{2}} \mathbf{O}_{\mathbf{2}}[\mathbf{m M}]\end{array}$ & $\mathbf{p H}$ & $\begin{array}{c}\text { Efikasnost Fenton- } \\
\text { sličnog procesa [\%] }\end{array}$ \\
\hline 1 & 20 & 0,75 & 11 & 6 & 4,27 \\
\hline 2 & 180 & 0,75 & 6 & 2 & 83,45 \\
\hline 3 & 20 & 30,375 & 11 & 2 & 77,66 \\
\hline 4 & 100 & 30,375 & 6 & 6 & 24,07 \\
\hline 5 & 100 & 0,75 & 1 & 2 & 68,5 \\
\hline 6 & 180 & 0,75 & 11 & 10 & 3,49 \\
\hline 7 & 20 & 60 & 6 & 10 & 3,11 \\
\hline 8 & 20 & 0,75 & 1 & 10 & 1,67 \\
\hline 9 & 100 & 60 & 11 & 10 & 43,05 \\
\hline 10 & 180 & 60 & 11 & 2 & 7,3 \\
\hline 11 & 180 & 30,375 & 1 & 10 & 53,48 \\
\hline 12 & 20 & 60 & 1 & 2 & 11,05 \\
\hline
\end{tabular}

Primenom softvera JMP 13 (SAS Institute) izvršena je optimizacija eksperimenta koja za krajnji cilj ima maksimizaciju efikasnosti uklanjanja boje u odnosu na tehnološke uslove.

Optimizacija procesnih uslova izvršena je u okviru granica testiranih varijabli: $20 \leq \mathrm{x} 1 \leq 180,0,75 \leq \mathrm{x} 2 \leq 60,1 \leq \mathrm{x} 3 \leq$ $11,2 \leq \mathrm{x} 4 \leq 10$. Profil za predikciju sa optimalnim vrednostima je prikazan na slici 2 .
$\mathrm{Na}$ osnovu dobijenih rezultata ustanovljeni su sledeći otpimalni uslovi: koncentracija boje $20 \mathrm{mg} / \mathrm{l}$, koncentracija nZVI $25,59 \mathrm{mg} / \mathrm{l}$, koncentracija vodonik peroksida $6,89 \mathrm{mM}$ i pH vrednost 2, pri čemu statistički model predlaže efikasnost procesa od $87,24 \%$. Dobijeni rezultati ukazuju na to da se efikasnost procesa dekolorizacije značajno povećava sa smanjenjem $\mathrm{pH}$ vrednosti i koncentracije boje. 


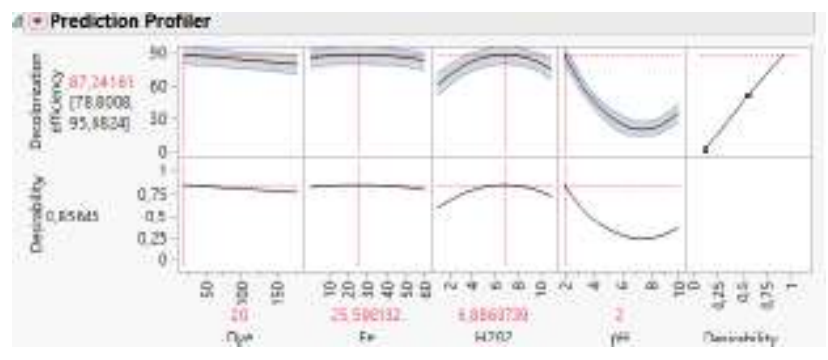

Slika 2. Optimalni uslovi Fenton-sličnog procesa

Rezultati analize potvrđuju da inicijalna koncentracija boje i koncentracija vodonik peroksida ostvaruju signifikantnu interakciju, što je ilustrovano dijagramom odzivne površine (slika 3). Dijagram odzivne površine ukazuje na činjenicu da se maksimalna efikasnost obezbojavanja postiže pri najnižoj koncentraciji boje od $20 \mathrm{mg} / \mathrm{l}$, pri čemu kontinuirano povećanje koncentracije boje dovodi do izrazitog smanjenja efikasnosti procesa. Drugi značajni faktor $u$ opisanoj interakciji je koncentracija vodonik peroksida, koji najviše ostvaruje sinergistički uticaj sa vrednošću $6 \mathrm{mM}$.

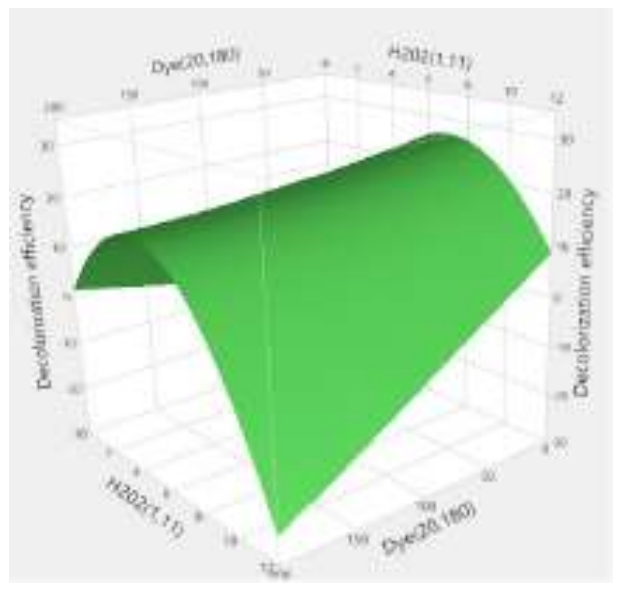

Slika 3. Dijagram odzivne površine statistički značajne dvofaktorske interakcije

\subsection{Tretman realnog efluenta}

U cilju utvrđivanja mogućnosti primene sintetisanog nanomaterijala, realan efluent generisan nakon procesa štampe i obojen cijan bojom je podvrgnut tretmanu primenom Fenton-sličnog procesa pri optimalnim dozama ispitivanih parametara. Efikasnost uklanjanja boje je praćena u periodu od 120 minuta, a rezultati su prikazani na slici 4.

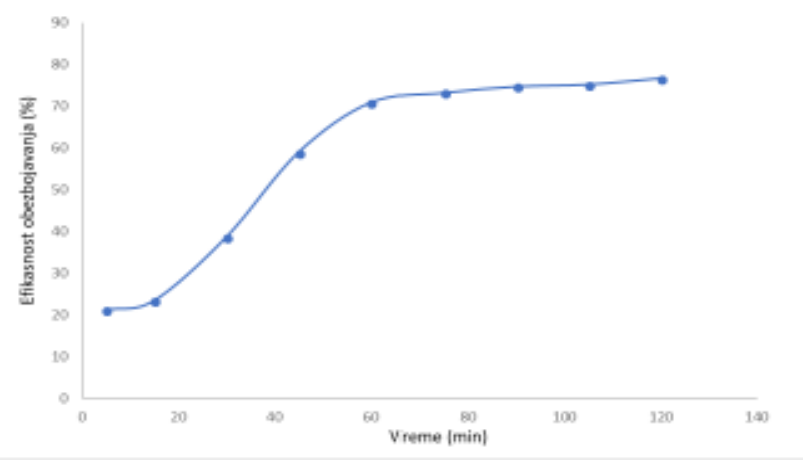

Slika 4. Zavisnost efikasnosti obezbojavanja od reakcionog vremena
Degradaciona efikasnost nakon 60 minuta je iznosila $70,85 \%$ za Fenton-sličan proces, pri čemu je maksimalna efikasnost tretmana postignuta pri dužem reakcionom vremenu, ali sa neznatnim povećanjem (do 76,69\%). U poređenju sa tretiranim sintetičkim rastvorom cijan boje, efikasnosti procesa u slučaju realnog efluenta su bile niže, što je posledica prisustva različitih jedinjenja $u$ kompleksnom matriksu efluenta. Brojne organske i neorganske vrste mogu da ostvare inhibitorni efekat na proces degradacije boje, ponašajući se kao hvatači hidroksil radikala i, na taj način, ostvarujući kompeticiju za aktivna mesta na površini katalizatora. Na osnovu dobijenih rezultata može se zaključiti da je sintetisan nanomaterijal ostvario veliki uspeh $\mathrm{u}$ tretmanu cijan grafičke boje.

U cilju potvrde dobijenih rezultata sprovedena je dodatna karakterizacija efluenta. U tabeli 2 su prikazani rezultati merenja osnovnih fizičko-hemijskih parametara, kao i HPK, BPK vrednosti i toksičnosti netretiranog efluenta i efluenta nakon tretamana.

Tabela 2. Fizičko-hemijska analiza realnog efluenta pre $i$ nakon tretmana

\begin{tabular}{|c|c|c|}
\hline Parametar & $\begin{array}{c}\text { Realan } \\
\text { efluent }\end{array}$ & $\begin{array}{c}\text { Fenton-sličan } \\
\text { proces }\end{array}$ \\
\hline $\mathrm{pH}$ & 8,20 & 2 \\
\hline Provodljivost $[\mu \mathrm{S} / \mathrm{cm}]$ & 523 & 860 \\
\hline Temperatura $\left[{ }^{\circ} \mathrm{C}\right]$ & 23,1 & 23,6 \\
\hline Mutnoća $[\mathrm{NTU}]$ & 19,41 & 12,04 \\
\hline $\mathrm{HPK}\left[\mathrm{mgO}_{2} \mathrm{~L}^{-1}\right]$ & 282,15 & 160,82 \\
\hline $\mathrm{BPK}\left[\mathrm{mgO}_{2} \mathrm{~L}^{-1}\right]$ & 0 & 15 \\
\hline $\begin{array}{c}\text { Toksičnost } \\
(\% \text { inhibicija })\end{array}$ & - & 13,30 \\
\hline
\end{tabular}

Na osnovu izmerenih vrednosti HPK i BPK, ustanovljeno je da je procenat smanjenja HPK za Fenton-sličan proces $43 \%$.

BPK vrednost je ispod granice detekcije, što potvrđuje činjenicu da je realan efluent nebiodegradabilan, te nije moguće primeniti nijedan biološki proces $u$ cilju postizanja visoke efikasnosti degradacije boje.

Povećana vrednost BPK nakon tretmana ukazuje na činjenicu da je došlo do formiranja određenog broja degradacionih produkata, što potvrđuje pretpostavku da uklanjanje boje iz rastvora i razgradanje hromoforne grupe ne znači obavezno i njenu potpunu oksidaciju do $\mathrm{CO}_{2}$ i $\mathrm{H}_{2} \mathrm{O}$.

Sprovođenjem testova toksičnosti na bakterijama Vibrio fischeri ustanovljeno je da netretirani efluent nije toksičan, a da nakon sprovedenih tretmana dolazi do blagog povećanja toksičnosti, verovatno kao posledica formiranja različitih degradacionih proizvoda reakcije. Ipak, izmerena vrednost inhibicije je niska, te tretirani efluent može da se ispusti u recipijent bez posledica za živi svet. 


\section{ZAKLJUČAK}

Dobijeni rezultati pokazuju da je postignut širok opseg efikasnosti obezbojavanja od $1,67-83,45 \%$ i samim tim je utvrđeno da sam proces uklanjanja boje u velikoj meri zavisi od primenjenih eksperimentalnih uslova.

Maksimalna efikasnost obezbojavanja postiže se pri najnižoj koncentraciji boje od $20 \mathrm{mg} / \mathrm{l}$, pri čemu kontinuirano povećanje koncentracije boje dovodi do izrazitog smanjenja efikasnosti procesa. Efikasnost Fenton procesa će se povećati sa većom koncentracijom katalizatora gvožđa, koja u ovom slučaju potiče od nZVI, ali i sa visokom koncentracijom $\mathrm{H}_{2} \mathrm{O}_{2}$, što dovodi do veće proizvodnje $\mathrm{OH}$ radikala i brze degradacije boje.

Pored koncentracije katalizatora, i $\mathrm{pH}$ vrednost $\mathrm{u}$ velikoj meri utiče na efikasnost uklanjanja boje Fenton procesom. Uprkos činjenici da izvođenje procesa u izrazito kiseloj sredini pri pH 2 nije povoljno sa aspekta zaštite životne sredine, $\mathrm{u}$ ovom istraživanju optimalna $\mathrm{pH}$ vrednost 2 je uslovila i veću efikasnost procesa u poređenju sa neutralnom ili alkalnom sredinom.

Statistički model predviđa da će efikasnost Fenton-sličnog procesa opasti na $25 \%$ i $34 \%$ za pH 6 i 10 , respektivno.

Nakon 60 minuta degradaciona efikasnost realnog efluenta je iznosila $70,85 \%$ za Fenton-sličan proces. U poređenju sa tretiranim sintetičkim rastvorom cijan boje, efikasnosti procesa u slučaju realnog efluenta su bile niže, što je posledica prisustva različitih jedinjenja u kompleksnom matriksu efluenta.

Na osnovu dobijenih rezultata može se zaključiti da je sintetisan nanomaterijal ostvario veliki uspeh u tretmanu cijan grafičke boje.

\section{LITERATURA}

[1] D. Mijin, Grafičke boje i lepkovi, Tehnološko metalurški fakultet, Beograd, 2015.

[2] M. Klavarioti, D. Mantzavinos, D. Casinos, "Removal of residual pharmaceuticals from aqueous systems by advanced oxidation processe", Environmental International, Vol. 35, pp. 402-417, 2009.

[3] D. Tomašević, "Primena stabilizovanog nano nula valentnog gvožđa i komercijalnih imobilizacionih agenasa za remedijaciju sedimenta kontaminiranog metalima", Doktorska disertacija, Prirodnomatematički fakultet, Univerzitet u Novom Sadu, Novi Sad, 2013.

[4] S. Machado, J.G. Pacheco, H.P.A. Nouws, J.T. Albergaria, C. Delerue-Matos, "Characterization of green zero-valent iron nanoparticles produced with tree leaf extracts", Science of the Total Environment, Vol. 533, pp. 76-81, 2015.

\section{Kratka biografija:}

Vanja Milovanović rođena je u Derventi 1989. godine. Diplomski rad na Fakultetu tehničkih nauka iz oblasti Grafičko inženjerstvo i dizajn odbranila je 2015. god.

dr Miljana Prica je u zvanju vanrednog profesora je od 2014. godine na Fakultetu tehničkih nauka u Novom Sadu na Departmanu za Grafičko inženjerstvo i dizajn. 